\title{
Lower Limb Amputations- A Necessary Evil- An Observational Study from a North Indian Tertiary Care Hospital
}

\author{
Utkarsh Garg ${ }^{1}$, Ram Gopal Sharma², Karishma Bansal ${ }^{3}$, Kritesh Goel ${ }^{4}$, Hardik Brahmbhatt ${ }^{5}$
}

${ }^{1}$ Department of General Surgery, M. M Deemed to be University, Ambala, Haryana, India. ${ }^{2}$ Department of General Surgery, M. M Deemed to be University, Ambala, Haryana, India. ${ }^{3}$ Department of Anaesthesiology, M. M Deemed to be University, Ambala, Haryana, India. ${ }^{4}$ Department of General Surgery, M. M Deemed to be University, Ambala, Haryana, India. ${ }^{5}$ Department of General Surgery, M. M Deemed to be University, Ambala, Haryana, India.

\section{ABSTRACT}

\section{BACKGROUND}

Limb loss to amputation is a major problem especially in developing countries where majority of the cases are preventable. It is a burden, not just for the patient, but also for their care givers which imposes tremendous financial and psychological burden upon them. The aim was to outline the patterns, indications and complications of lower limb amputations among patients admitted to MMIMSR, Mullana, Ambala, India, which is a tertiary care centre.

\section{METHODS}

This was a prospective, observational study that was conducted at MMIMSR, Ambala, for a period of 18 months. 50 patients underwent lower limb amputations in our hospital during the study period.

\section{RESULTS}

The age ranged between 23 to 85 years. Males outnumbered females by a ratio of 4.5:1. Toe disarticulations were the most common. Diabetes mellitus (DM) was the most common cause (62\%) followed by Non-DM peripheral vascular disease (PVD) $(22 \%)$. Two patients expired in the post-operative period. Infection of the stump was the most common local complication in the post-operative period. Hospital stay ranged from 6 days to 40 days.

\section{CONCLUSIONS}

Although trauma is still the most common cause of lower limb amputations (LLA) in the developing nations, amputations for complications of diabetes is on the rise and may be the leading aetiology in future. Diabetic gangrene followed by PVD were the common causes of amputation in our settings. The study shows that most of the causes are potentially avoidable. Community health education programmes that are primarily focussing on road safety measures, early presentation to the physician and good diabetic control are pivotal to decrease the incidence of amputations for preventable indications.

\section{KEY WORDS}

Lower Limb Amputation, Diabetes, Peripheral Vascular Disease, Gangrene
Corresponding Author: Karishma Bansal, \#226, 227, Bansal Nursing Home, Sector-14, Sonepat-131001, Haryana, India.

E-mail: karishmabansal60@gmail.com

DOI: $10.14260 /$ jemds/2020/214

Financial or Other Competing Interests: None.

How to Cite This Article: Garg U, Sharma RG, Bansal K, et al. Lower limb amputations- a necessary evil- an observational study from a North Indian tertiary care hospital. J. Evolution Med. Dent. Sci. 2020;9(12):995-999, DOI: $10.14260 / \mathrm{jemds} / 2020 / 214$

Submission 16-01-2020,

Peer Review 25-02-2020,

Acceptance 04-03-2020,

Published 23-03-2020.

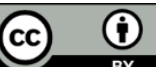




\section{BACKGROUND}

Amputation is the removal of the whole or part of a limb by cutting through bone or joint. A major amputation is one that is performed proximal to the ankle or wrist. An ancient surgical procedure, amputation retains its relevance in modern time to save life or remove a dead or useless limb. Knowledge of indications and complications of amputation is helpful in instituting timely and preventive strategies. Indications for amputation vary between and within countries. ${ }^{1}$ In India it is estimated that 75, 52,494 of population are undergoing lower limb amputation (LLA) per year. Most amputations are performed for ischemic disease of the lower extremity. In 1965, the ratio of above-knee amputation/s (AKA) to below-knee amputation/s (BKA) was 70:30. A quarter century later, it became $30: 70 .{ }^{2}$ The estimated amputations in the world are approximately more than a million, out of which $70 \%$ are due to Diabetes Mellitus. Not only the impact of amputation is devastating to their lives, it is also one of the costliest complications, as foot problems are the commonest problems of hospital admissions for people with diabetes. ${ }^{3}$

Around $40 \%$ of diabetic individuals who have undergone one amputation will require a contralateral amputation within a span of 3 years unless strict glycaemic control is achieved. ${ }^{4}$ and mortality rate in a year after LLA of $11 \%-41 \%$ increases to $20 \%-50 \%$ after 3 years and 39\%-68\% after 5 years. ${ }^{5}$ Amputation is one of the most ancient of all surgeries dating back to as far as the 16 th century. ${ }^{6}$ Amputation as a surgical option is the last resort in situation where salvage of the part is impossible, and the remaining part of the tissue requires excision.7,8 It was also a common punishment in some societies on the basis of religious grounds. It is regarded that the earliest record of amputation as a useful medical technique is found in the Hippocratic disquisition. The ancient amputations usually resulted in mortalities from shock either due to loss of blood and/or infection. Survivors of the procedure itself succumbed to death in the early postoperative period either due to sepsis and/or gangrene. ${ }^{9}$

Amputation is the only surgery ever to have a record $300 \%$ mortality rate in a single procedure, a pioneering Scottish surgeon going by the name of Robert Liston, in an attempt to accomplish the fastest ever amputation to be done in under 2 and a half minutes, resulted in mortalities of the intended patient due to gangrene, his assistant whose fingers Liston severed accidentally during the procedure and who eventually died of blood loss and gangrene and lastly mortality of a spectator who was watching this history being made, as Liston's knife slashed through the coat of the spectator who actually thought that it had slashed through his body and ultimately died of shock. Twenty-nine years have elapsed since the St. Vincent Declaration had set a 50\% reduction of LLA as a principal target in diabetic patients, and the worldwide situation is far wide from the goal. ${ }^{10}$ Indeed, every 30 seconds a lower limb is amputated because of diabetes somewhere in the world. ${ }^{11}$

\section{METHODS}

This is an observational study which was done at tertiary care centre in Ambala, India, from 2017-2019. A minimum of 50 patients admitted in surgery wards who had undergone amputations and disarticulations in lower limb were analysed based on various parameters. Detailed history was taken, examination was done, and findings were noted. The following parameters of all the patients who had lower limb amputation (LLA) during this period were recorded: Age, sex, indication for amputation, level of amputation and complications, time for recovery.

\section{Inclusion Criteria}

Patients of 18 years of age and above, who had undergone any kind of amputation and/or disarticulation in lower limbs were included in the study.

\section{Exclusion Criteria}

- Cases of upper limb amputations and/or disarticulations.

- Cases of tumours/malignancy undergoing amputations.

- Patient refusal.

The study protocol was reviewed by the Ethical Committee of Hospital and was granted ethical clearance. After explaining the purpose and details of the study, a written informed consent was obtained from the patients who participated in the study. It was emphasized that strict confidentiality would be maintained at all times and the patients could withdraw at any time without being penalized.

\section{RESULTS}

Over a period of 18 months, 50 LLAs were performed. Age of the patients ranged from 23 to 85 years with an average age of 55.74 years (table II). $82 \%$ of the amputees were males (table I). Diabetic foot complications were the most common indication for LLA in our series. Followed by peripheral arterial occlusive disease and also there were a few cases of trauma (figure I). Toe disarticulation was the most common type, followed by transtibial amputation and trans femoral (table III). Infection was the most common complication that involved 7 amputation stumps, followed by psychosocial disturbances which occurred in 6 patients. All the infected stumps required debridement with suturing and only $8 \%$ required a revision amputation at a more proximal level. There was a $4 \%$ mortality noted during the study period (figure II).

\begin{tabular}{|ccc|}
\hline Sex & No. of Cases & Percentage \\
F & 9 & $18.0 \%$ \\
M & 41 & $82.0 \%$ \\
Total & $\mathbf{5 0}$ & $\mathbf{1 0 0 . 0} \%$ \\
\hline \multicolumn{3}{|c|}{ Table I. Sex Distribution of Patients } \\
\hline
\end{tabular}

\begin{tabular}{|ccc|}
\hline Age (Years) & No. of Cases & Percentage \\
$<40$ & 4 & $8.0 \%$ \\
$41-50$ & 12 & $24.0 \%$ \\
$51-60$ & 22 & $44.0 \%$ \\
$>60$ & 12 & $24.0 \%$ \\
Total & $\mathbf{5 0}$ & $\mathbf{1 0 0 . 0} \%$ \\
\hline \multicolumn{2}{|c|}{ Table II. Age Distribution of Patients } \\
\hline
\end{tabular}


As evident from Table II, the mean age of the patients was 55.74 years (range of 23 years to 85 years), with majority of them in the age group of 51-60 years (44\%) followed by a bimodal distribution of patients in age groups classes of 41 50 years and above 60 years being $24 \%$.

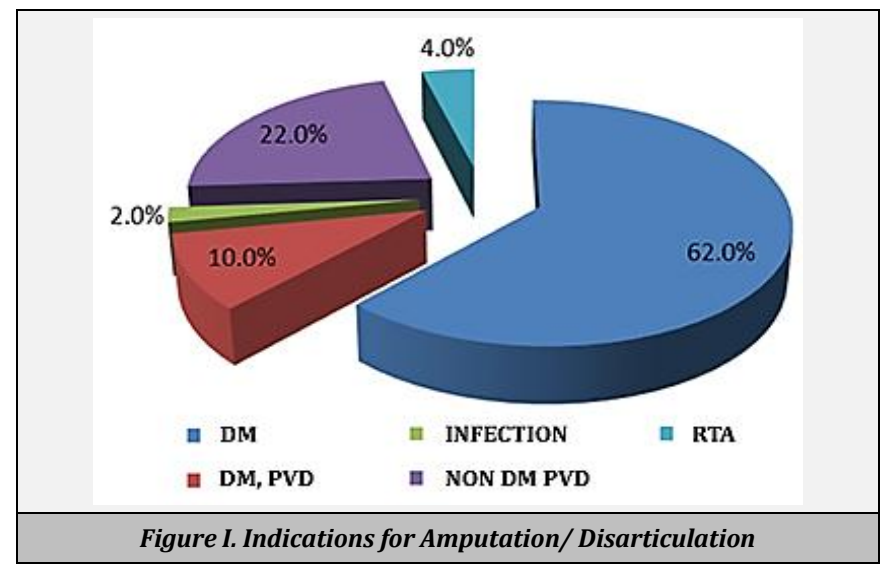

As Figure I suggests, DM was the most common cause for amputations $(62 \%)$ followed by Non-DM peripheral vascular disease (22\%). $10 \%$ of amputations were seen in DM PVD patients and traumatic amputations were mainly secondary to crush injuries from road traffic accidents (4\%). There was only one case of infection.

\begin{tabular}{|ccc|}
\hline Amputation Level & No. of Cases & Percentage \\
BKA & 15 & $30.0 \%$ \\
AKA & 2 & $4.0 \%$ \\
Mid Tarsal & 2 & $4.0 \%$ \\
Tarsometatarsal & 1 & $2.0 \%$ \\
TMA & 3 & $6.0 \%$ \\
Disarticulation Level & 26 & $52.0 \%$ \\
TOE & 1 & $2.0 \%$ \\
KNEE & $\mathbf{5 0}$ & $\mathbf{1 0 0 . 0} \%$ \\
Total & & \\
\hline Table III. Levels of Amputation/Disarticulation \\
\hline
\end{tabular}

As Table III indicate, majority of the procedure done was disarticulation (54\%) out of which disarticulation of the toe was maximum (52\%) and only one case of knee disarticulation (2\%). A total of 23 (46\%) cases had undergone amputation/s majority of which was BKA (30\%), $3(6 \%)$ cases were TMA followed by $2(4 \%)$ cases each of AKA and mid tarsal (Chopart's) amputation. Only 1 (2\%) case was of tarsometatarsal (Lisfranc's) amputation.

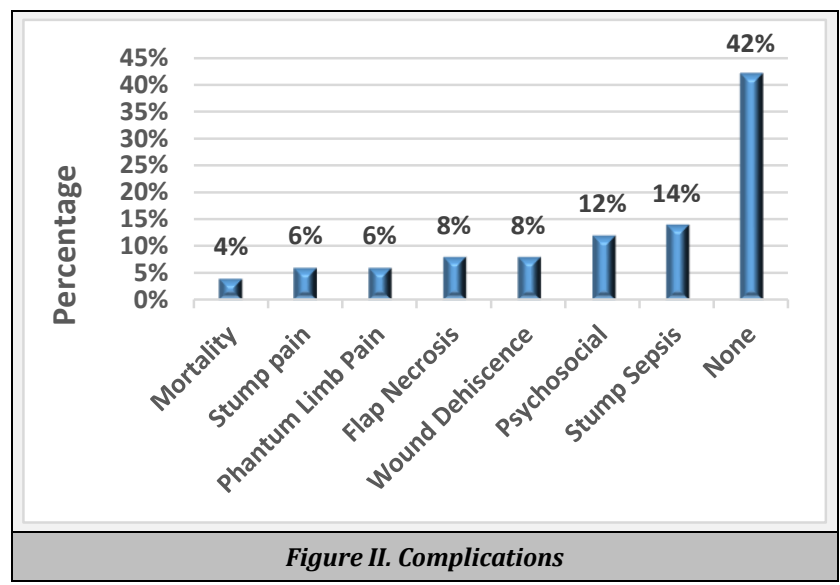

As evident from Figure II, there were no complications in majority of cases (42\%) followed the stump sepsis (14\%) closely followed by psychosocial problems (12\%). Flap necrosis and wound dehiscence accounted for $8 \%$ each of all the complications and phantom limb pain and stump pain being $6 \%$ each respectively. The overall mortality amongst 50 cases was $2(4 \%)$ which was seen in a case of BKA and TMA each. $36 \%$ cases completely recovered in a span of $<10$ days after post-op which comprised of all minor toe disarticulations, further closely followed by 11-20 days range of recovery which comprised of $34 \%$ cases. About 13 (26\%) cases required $>20$ days to recover completely which mainly included major amputations/disarticulation.

\section{DISCUSSION}

About $10 \%$ of the population of the world has some kind of disability or impairment. ${ }^{12}$ The Global Burden of Disease, defines disability as loss of health in terms of functional capacity in relation to mobility, cognition, hearing and vision. ${ }^{13}$ In, India there are many people suffering from various disabilities, around 0.62 amputees have been reported per thousand population. ${ }^{14}$ Amputation is required as a lifesaving as well as a limb saving operation. ${ }^{15}$ Care of amputees is complex, which includes not just a mere operation and hospital care but rehabilitation, limb fitting, domestic and social readjustment as well. ${ }^{16}$

Various techniques of management are difficult and can possibly improve, such as:

- selection of level of amputation is sometimes difficult for example, too distal a procedure may require revision surgery, and too proximal an amputation may eventually cause reduction of mobility.

- attempts at salvage by aggressive arterial reconstruction have caused to affect the level of subsequent amputation. ${ }^{16-19}$

Inappropriate requests of prosthesis may lead to unused artificial limb, even after which a small fraction of the amputees regain normal mobility. ${ }^{20}$ The estimated amputations in the world are approximately more than a million, out of which $70 \%$ are due to Diabetes mellitus (DM). Not only the impact of amputation is devastating to their lives, it is also one of the costliest complications, as foot problems are the commonest problems of hospital admissions for people with diabetes. Amputation is a serious health onus on the families, society and medical services. It causes a major impact on patient's psychology as the individual can no longer support self and family. ${ }^{21}$ Amputation can cause mood swings not because of loss of limb but also due to the limitation of work and major changes in the individual's lifestyle. After amputation the patient can go in depression because of many factors like limb loss, selfstigma, work limitation etc. ${ }^{22,23}$

Many people regard amputation of a limb as a catastrophic disability; one which produces a profound emotional response due to its effect on the body image as well as a serious loss of functional ability. Therefore, it is crucial to managing prospective amputees that counselling be given prior to amputation on the possibilities of functional 
restoration and outlook for the future. The success of the procedure depends on the input of a multidisciplinary team and close liaison with the operating surgeon. The patient's knowledge of the rehabilitation process improves participation and helps determine the outcome goals. ${ }^{24}$

Rehabilitation of LLA patients includes the preamputation, postoperative, pre-prosthetic and prosthetic rehabilitation stages, during which an amputee is provided with a prosthesis. During this portion of time an amputee tries to adjust to the prosthetic aiding device and attain the restoration of ambulation and other locomotive abilities with the help of the prosthetic device. Medical rehabilitation should go hand in hand along with ample psychological and social rehabilitation, so as to achieve the ultimate aim of rehabilitation, that is, to successfully re-establish an amputee into everyday life as much as possible almost to the level of pre-amputation daily. Rehabilitation helps to attain the maximal possible emotional, physical, vocational, social and financial independency of an amputee and maximum efficiency in all aspects of life. One of the factors that enable the successful outcome of limb amputee's rehabilitation is an interdisciplinary, well-organised and harmonious teamwork of physiotherapists, occupational therapists, nurse, psychologist and a social worker.

Experiences of an amputee is not only the loss of an anatomic part of the body, but also loss of functions for e.g. changes in coordination, impairment of balance, proprioception and changes in weight distribution. The goal of rehabilitation is to acquire prime independence in mobility and self-care activities and to conquer over all physical, psychological, social and vocational issues. Tailor - made programmes for each person addressing their specific needs should be made available. Family's approval to change and readiness to modify the home environment as per the convenience of the specific needs of the amputee and the patient's capability to cope up with the mobility aids such as a wheelchair or prosthesis needs to be discussed before the patient is discharge. For the educational age group, focus should be on reinforcing tactics to face systemic challenges and environmental barriers. For the employed group, vocational guidance and counselling followed by vocational judgement, job assessment with workplace adjustments and suitable job placements should be included into the rehabilitation plan. If the person is a home maker, the rehabilitation should focus on how he/she can handle the affairs of the home such as child-rearing, cooking and other household chores.

\section{Steps to Equip a Person to be Self-Reliant}

1. Improving the support system

2. Getting involved in physical activities (exercise and selfcare)

3. Joining a self - help group

4. Obtaining guidance and counselling from a professional

5. Rebuilding a sense of well - being, purpose and to acquire dignity and worth.

Regular follow ups are required for a successful rehabilitation. The family members should also be involved as per the nature of problems. ${ }^{25}$

\section{CONCLUSIONS}

Limb amputations are very common surgical procedures due to various conditions affecting the limbs. Basic data of these cases in this tertiary care hospital of North India is lacking. The study aims at evaluating cases of lower limb amputations so as to accumulate/procure basic data and to evaluate whether this study can help in better management and outcome of such patients. Proper education, good hygiene, glycaemic control in diabetics, early recognition of problem and its effective management, and an extensive rehabilitation programme can help one avoid this necessary evil and its dire consequences.

\section{REFERENCES}

[1] Ajibade A, Akinniyi OT, Okoye CS. Indications and complications of major limb amputations in Kano, Nigeria. Ghana Med J 2013;47(4):185-8.

[2] World statistics on amputation. (Date of assess 26 November 2009). www.WHOworldstatistics.com

[3] Most RS, Sinnock P. The epidemiology of lower extremity amputations in diabetic individuals. Diabetes Care 1983;6(1):87-91.

[4] Apelqvist J, Larsson J, Agardh CD. Long-term prognosis of diabetic patients with foot ulcers. J Intern Med 1993;233(6):485-91.

[5] Apelqvist J, Ragnarson-Tennvall G, Persson U, et al. Diabetic foot ulcers in a multidisciplinary setting. An economic analysis of primary healing and healing with amputation. J Intern Med 1994;235(5):463-71.

[6] Kim YC, Park CI, Kim DY, et al. Statistical analysis of amputations and trends in Korea. Prosthet Orthot Int 1996;20(2):88-95.

[7] Uustal H. Lower limb amputation, rehabilitation and prosthetic restoration. In: Maitin IB, Cruz E, eds. Current diagnosis and treatment: physical medicine and rehabilitation. New York: McGraw-Hill Education 2015.

[8] Smith DG, Skinner HB. Amputations. Chap - 11. In: Skinner HB, McMahon PJ, eds. Current diagnosis and treatment in orthopedics. $5^{\text {th }}$ edn. New York: The McGraw-Hill Companies, 2014.

[9] Canale ST, Beaty JH. Campbell's operative orthopaedics. Vol. 1. 12th edn. Mosby Inc., 2012: p. 598-9, 604-5, 63846, 2563-73.

[10] Diabetes care and research in Europe: the Saint Vincent declaration. Workshop report. Diabet Med 1990;7(4):360.

[11] International Diabetes Federation and International Working Group of the Diabetic Foot. In: Bakker K, Foster $\mathrm{AV}$, van Houtoum $\mathrm{WH}$, et al. eds. Time to Act. The Netherlands: International Diabetes Federation 2005.

[12] World Health Organization. Disability and rehabilitation: WHO action plan 2006-2011. Geneva: World Health Organization, 2005.

[13] World Health Organization. Global burden of disease report. Geneva: World Health Organization, 2004.

[14] Mohan D. A report on amputees in India. Orthot Prosthet 1986;40(1):16-32. 
[15] Williams SN, Bulstrode CJ, O'Connell PR. Bailey and Love's Short practice of surgery. 26 $6^{\text {th }}$ edn. Florida: CRC Press 2013: p. 891-3.

[16] Dardik H, Kahn M, Dardik I, et al. Influence of failed vascular bypass procedures on conversion of belowknee to above-knee amputation levels. Surgery 1982;91(1):64-9.

[17] Sethia KK, Berry AR, Morrison JD, et al. Changing pattern of lower limb amputation for vascular disease. Br J Surg 1986;73(9):701-3.

[18] Evans WE, Hayes JP, Vermilion BD. Effect of a failed distal reconstruction on the level of amputation. Am J Surg 1990;160(2):217-20.

[19] Stirnemann P, Walpoth B, Wursten HU, et al. Influence of failed arterial reconstruction on the outcome of major limb amputation. Surgery 1992;111(4):363-8.

[20] Houghton AD, Taylor PR, Thurlow S, et al. Success rates for rehabilitation of vascular amputees: implications for preoperative assessment and amputation level. Br J Surg 1992;79(8):753-5.
[21] Sahu A, Sagar R, Sarkar S, et al. Psychological effects of amputation: a review of studies from India. Ind Psychiatry J 2016;25(1):4-10.

[22] Durmus D, Safaz I, Adigüzel E, et al. The relationship between prosthesis use, phantom pain and psychiatric symptoms in male traumatic limb amputees. Compr Psychiatry 2015;59:45-53.

[23] Mckechnie PS, John A. Anxiety and depression following traumatic limb amputation: a systematic review. Injury 2014;45(12):1859-66.

[24] Burgess EM. Amputation surgery and postoperative care: rehabilitation management of amputees. Baltimore: Williams \& Wilkins 1982: p. 17-44.

[25] Ida K, Neven K, Ognjen Z, et al. Rehabilitation of lower limb amputees. Period Biol 2015;117(1):147-59. 